International Journal of Agriculture, Environment and Bioresearch

Vol. 4, No. 03; 2019

ISSN: $2456-8643$

\title{
CAULIFLOWER (Brassica oleraceavar. botrytis L.) PRODUCTION APPLIED WITH BIO- ORGANIC PESTILIZER FROMPLANT EXTRACTS ANDANIMAL WASTES: EFFECTS ON GROWTH AND YIELD
}

\author{
Leah C. Tuan \\ *Associate Professor, Department of Agricultural Sciences, College of Agriculture, Fisheries, and Natural \\ Resources, University of Eastern Philippines, University Town, Northern Samar, Philippines
}

http://doi.org/10.35410/IJAEB.2019.360369

\begin{abstract}
Selected botanicals and carabao manure used as biopestilizer was studied for three months at the University Demo Farm, University of Eastern Philippines, Main Campus, University Town, Catarman, Northern Samar, Philippins to determine their effect on the growth and yield of cauliflower. The application of bio-organic pestilizers from animal wastes and plant extracts was found to have highly influenced on the growth and yield of cauliflowers, evident on the different growth and yield parameters evaluated. Higher rates of bio-organic pestilizer resulted to bigger and heavier plants and eventually higher yield of marketable cauliflowers. Bio-organic fertilizer from animal wastes (carabao manure with manure tea) was found effective in influencing growth and yield of cauliflower while the efficacy and effectiveness of bio-organic fertilizer from plant extracts might have been affected by factors like dose, timing of and frequency of application, and stress factors brought about by abnornal environmental conditions during the conduct of the study.

The use of bio-organic fertilizer from animal wastes and plant extracts has high potential as an alternative sources of plant nutrients for sustainable organic cauliflower production under favorable weather condtions. A follow-up study is necessary to verify its economic viability and feasibility under farmers' field at various agroclimatic conditions in Northern Samar, Philippines
\end{abstract}

Keywords: Animal wastes, Bio-organic pestilizer, Carabao manure, Plant extracts.

\section{INTRODUCTION}

Among the problems that beset agriculture are loss of soil productivity from excessive soil erosion, surface and ground water pollution from pesticides, fertilizers and sediments, impending shortages of non- renewable resources, insect pest infestation and low farm income from depressed commodity prices and high production costs.

Some of the many ways to address these farm conditions vary from promotion of soil fertility, conservation of biodiversity (e.g. native flora and fauna), production methods that are adapted to the locality, and avoidance of chemical inputs. Such methods help to stabilize the delicate ecosystems and reduce drought sensitivity and pest infestations. These are some common sets of practices farmers are trying to take for a more sustainable approach, in part through greater use 
of on-farm or local resources each contributing in some way to long- term profitability, environmental stewardship and rural quality of life.

The basic challenge for sustainable agriculture is to make better use of internal resources for profitable and efficient production with emphasis on integrated farm management and conservation of soil, water and biological resources. Animal manure and some indigenous botanicals are locally abundant resources that can be tapped as alternatives to synthetic fertilizers and pesticides to address the necessity. Manure produced by livestock activity is an unwanted product capable of causing serious environmental pollution. Agronomic management practices on the use of manure may transform the target from a waste to a resource product. Studies have proven that processed animal manure can replenish nutrients required by crops and supply the soil with essential organic matter. Closed nutrient cycles and efficient use of local resources for example compost, dung or seeds - are especially important for subsistence farmers depending on few and limited resources.

On the other hand, plant extracts have long been used to control insects. The first botanical insecticide dates back to the 17th century, when it was shown that nicotine from tobacco leaves killed plum beetles. Botanicals are noted to have broad-spectrum activity, relatively specific in their mode of action and also easy to process and use.

In the recent years, reports revealed that several vegetable farmers have already shunned themselves from adopting the conventional means. Many of them have shared good testimonies and successful stories about growing crops the organic way.

Among the tried and tested organic farming practices by seasoned farmers are: use of fermented plant juices as soil drench to supply nitrogen to young plants, thorough and patient preparation of the field with organic fertilizer, and use of herbal-based pesticides (Rodriguez, 2012; Samonte, 2012; Samonte, 2013).

Farmers have proven that shifting from conventional to natural farming is economically viable; that organic farming has not just enabled them to save production cost but more so has restore the natural fertility of the soil, save and promote healthier environment and most of all produce chemical-free food on their table.

This study tried to test specific bio resources, i.e. manure and botanicals as fertilizer and as pesticide for cauliflower production in Northern Samar.

\section{METHODOLOGY}

\section{Experimental Design and Treatments.}

A $3 \times 4$ factorial experiment in a randomized complete block design (RCBD) with three replications was used. Three doses of bio-organic fertilizer from animal were used to wit: No carabao manure (DCM0-control); $1.0 \mathrm{~kg}$ dried carabao manure (DCM1) and $1.5 \mathrm{~kg}$ dried carabao manure (DCM1.5) and four dosages of foliar bio-pestilizer from plant extracts namely: No Biopestilizer (B0-control); with bio- fertilizer (B1); with bio-pesticide (B2) and bio-pestilizer (B3). The treatments were designated as follows: 
T1: MOBO $\quad$ - No DCM, No Biofer, and No BioPes - (Control)

T2: $\quad$ MOB1 - No $\quad$ DCM + BioFer

T3: $\quad$ MOB2 - No DCM + BioPes

T4: $\quad$ MOB3 - No DCM + BioPestilizer

T5: $\quad$ M1BO - DCM1, No Biofer, and No BioPes T6: $\quad$ M1B1 - DCM1 + BioFer

T7: $\quad$ M1B2 - DCM1 + BioPes

T8: $\quad$ M1B3 - DCM1 + BioPestilizer

T9: M2BO - DCM1.5, No Biofer, and No BioPes T10: M2B1 - DCM1.5 + No Biofer

T11: M2B2 - DCM1.5 + BioPes

T12: M2B3 - DCM1.5 + BioPestilizer

Preparation and Application of Carabao Manure as Bio-organic Fertilizer. Carabao manure was processed in two ways: dried (DCM) and manure tea (CMT). Dried carabao manure was collected and air-dried until it was totally dried, while carabao manure tea was processed using a sack full of partially dried carabao manure submerged in a 200-liter ground water for one week before its use.

Dried carabao manure (DCM) was prepared in two levels: 33 and $50 \mathrm{t} / \mathrm{ha}$ converted into $1.0 \mathrm{~kg}$ (DCM1) and $1.5 \mathrm{~kg}$ (DCM1.5), respectively. Application of DCM was done once for DCM1 and twice for DCM1.5. Application of DCM1 was adminstered as basal before planting; while second application for DCM1.5 as top dress was done 10 days after the first application. Carabao manure tea (CMT) at the rate of $100 \mathrm{ml}$ plant was applied in each plant in all treatments at planting and at weekly interval thereafter throughout the duration of the study. Application was directed in the soil at the base of each plant.

Preparation and Application of Bio-Fertilizer and Bio-Pesticide from Plant Extract. Malungay(Moringa oleifera), madre de cacao (Gliricidia sepium) and Ipil-ipil (Leucaena leucocephala) leaves were collecetd and processed into an organic foliar fertilizer. The fresh leaves were chopped into small pieces to facilitate fermentation. Chopped leaves was mixed with equal amount ground water and brown sugar at 1:1:1 ratio. The mixture was allowed to ferment for seven days prior to its use. The same process was used for akapulko (Casia alata) and quava (Psidiumguajava) as source of bio-organic pesticide. The fermented bio-pesticide was mixed with fresh extracts from $100 \mathrm{~g}$ ground hot pepper fruits for every liter of the mixture, 6 hours prior to its use.

Sixty milliliters (modified from PCAARRD Farm Primer, 2015) of fermented bio- fertilizer from plant extracts was mixed with $1,000 \mathrm{ml}$ of distilled water, was applied twice a week throughout 
the duration of the experiment. On the other hand, foliar bio-pesticide was directly applied to the plants every after three days throughout the duration of the experiment.

Planting and Harvesting. Hardened cauliflower seedlings (Farmers' Extra Early variety) were transplanted to the plastic pots filled with desired volume of soil medium and bio-organic fertilizer late in the afternoon to reduce transplanting shock. The plants were maintained using recommended cultural management practices. Gowth and yield was measured in terms of plant height, length and width of leaves, leaf area and weight at harvest, weight of whole plant, rootshoot-ratio, number of days to $50 \%$ flowering, weight and diameter of curd and yield of marketable curds. Harvesting was done when the curd became compact and firm or about 50 days from transplanting. Data gathered were analyzed employing the analysis of variance (ANOVA) and treatment mean differences were determiend using the Duncans Multiple range Test (DMRT) at 5\% level of probability.

\section{RESULTS AND DISCUSSION}

\section{Growth Characters}

Growth characters as influenced by the application of bio-organic pestilizer from animal wastes and plant extracts are summarized in Table 1.

Plant height.Plant height at harvest differed significantly as influenced by the application of bioorganic pestilizer. Generally, cauliflowers were tallest, $41.24 \mathrm{~cm}$, when applied with bio-organic pestilizer (dried carabao + manure + foliar pestilizer), while cauliflower plants without biopestilizer significantly produced the shortest plants with $31.51 \mathrm{~cm}$.Varied responses in plant height among the treatments can be mostly attributed to the application of dried carabao manure (DCM) with carabao manure tea (CMT), rather than the application of foliar bio spray (FBS). Jigmei, N.J., et al., (2015) reported an increase in growth parameters of broccoli applied with chicken and manure tea; and El-Magd, et al., (2016), noted accelerated growth of the plants applied with organic manure.

Number of Leaves per Plant at Harvest. Number of leaves produced per plant varied according to levels of bio-organic pestilizer application, however, such variation was not significant. The production of almost the same number of leaves with or without the application of different levels of bio-organic pestilizer indicates that the cauliflower variety used in the study can adapt to local conditions even in soils with low fertility level. This observation is true in almost all vegetable (Brassica) researches in the area where the control (without fertilizer application) plants were able to develop considerable number of leaves but of different length, breadth and weight subject to available nutrients in the soil (Tuan, 2002).

Leaf Lengthat Harvest (cm).Length of cauliflower leaves was significantly affected by the application of bio-organic pestilizer. Longest leaves were recorded in M2B3, $22.17 \mathrm{~cm}$ while the shortest leaves were found in treatments without bio-organic pestilizer (M0B2, M0B3, M0B1, and M0B0, with $15.78 \mathrm{~cm}, 15.58 \mathrm{~cm}, 15.57 \mathrm{~cm}$, and $14.35 \mathrm{~cm}$ respectively). The rest of the treatments had leaf lengths ranging from 21.09 to $19.47 \mathrm{~cm}$. Findings of the study revealedthat higher rates of bio-pestilizer produced bigger and longer leaves.This corroborates the findings of 
Fayed (2010) who claimed that manure tea significantly increased the vegetative parameters of the Roghini olive trees. In addition, El-tantawy (2009) also found out that farmyard compost tea increased the height and leaf area of potato plant.

Leaf Width at Harvest (cm).Widest leaves was recorded in plants receiving the highest rates of bio-organic pestilizer (M2B3, 12.84cm, and $\mathrm{M} 2 \mathrm{~B} 0,11.70 \mathrm{~cm}$ ). Leaves were narrowest among plants not applied with bio-organic pestilizer (M0B2, M0B3, M0B0, and M0B1 with $9.28 \mathrm{~cm}$, $9.21 \mathrm{~cm}, 9.12 \mathrm{~cm}$ and $9.11 \mathrm{~cm}$, respectively). Leaf width of the rest of the treatments M2B2, M1B1, M1B2, M1B3, M2B1, and M1BO varied from $11.43-11.28 \mathrm{~cm}$, were significantly related.The production of wider leaves in cauliflower is necessary to support flower/curd formation. Results of this study revealed that formation of bigger and wider leaves is directly related to the application of bio-fertilizer from animal wastes (dried carabao manure and manure tea) and partly by the application of bio-pestilizer from plant extract as sources of nutrient. Gross et al.(2008), reported that ammonium is the major form of nitrogen present in the extract solutions from all manure types and that the nitrogen released after 14-day extraction by the different methods from the different manures ranged between 50\% and $85 \%$. Alo and Tuan (2015) obtained almost similar result in cauliflower applied with chicken dung.

Leaf Area at Harvest $(\mathbf{c m})$. Biggest leaf area was noted in plants in applied with bio- organic pestilizer from animal and plant extracts (DCM-1+ BioPes), with $226.51 \mathrm{~cm} 2$, while plants which were not treated with bio-pestilizer exhibited the smallest leaf area ranging from 146.97 $\mathrm{cm} 2$ to $127.81 \mathrm{~cm} 2$. The variation in leaf area observed among treatments being bigger in plants applied with bio-pestilizer from animal wastes (carabao manure and manure tea) implies the availability of sufficient nutrients. Nourishment received by the plants enabled the production of bigger and wider leaves; a plant requirement that allow optimum light interception and distribution for efficient physiologic process such as photosynthesis and carbohydrate transport (El-Sawy et al., 200; el-Dissoky, 2008) which contribute to the formation of reproductive parts in cauliflower. 
Table 1. Growth characters of cauliflower as influenced by the application of bio-pestilizer from animal wastes and plant extracts.

\begin{tabular}{|c|c|c|c|c|c|c|c|c|}
\hline \multirow{2}{*}{ Treatments } & \multicolumn{8}{|c|}{ Mean* } \\
\hline & $\begin{array}{l}\text { Plant } \\
\text { Height }(\mathrm{cm})\end{array}$ & $\begin{array}{l}\text { Number of } \\
\text { leaves per } \\
\text { plant }\end{array}$ & $\begin{array}{l}\text { Leaf Length } \\
\text { at harvest } \\
(\mathrm{cm})\end{array}$ & $\begin{array}{l}\text { Leaf width at } \\
\text { harvest }(\mathrm{cm})\end{array}$ & $\begin{array}{l}\text { Leaf area at } \\
\text { harvest }\left(\mathrm{cm}^{2}\right)\end{array}$ & $\begin{array}{l}\text { Leaf weight } \\
\text { at harvest } \\
\text { (g) }\end{array}$ & $\begin{array}{l}\text { Weight of } \\
\text { Whole } \\
\text { Plant }(\mathrm{g})\end{array}$ & $\begin{array}{l}\text { Root-Shoot } \\
\text { Ratio }\end{array}$ \\
\hline M0B0 & $35.51^{b c}$ & 16.60 & $14.35^{\mathrm{C}}$ & $9.12^{\mathrm{c}}$ & $146.97^{b}$ & $\mathbf{7 8 . 8 9}^{\text {bc }}$ & $24.79^{\text {abc }}$ & $4.66^{\mathrm{c}}$ \\
\hline M0B1 & $34.50^{c}$ & 15.80 & $15.58^{\mathrm{C}}$ & $9.11^{\mathrm{c}}$ & $127.81^{b}$ & $65.51^{c}$ & $19.66^{\mathrm{bcd}}$ & $5.29^{\mathrm{bc}}$ \\
\hline M0B2 & $35.00^{b c}$ & 16.73 & $15.78^{C}$ & $9.28^{c}$ & $128.93^{b}$ & $77.10^{b c}$ & $18.64^{\mathrm{abc}}$ & $9.90^{\mathrm{a}}$ \\
\hline M0B3 & $35.19^{b c}$ & 5.60 & $15.57^{\mathrm{C}}$ & $9.21^{\mathrm{c}}$ & $134.57^{\mathrm{b}}$ & $62.63^{\mathrm{c}}$ & $16.37^{d}$ & $7.22^{\mathrm{abc}}$ \\
\hline M1B0 & $40.47^{a}$ & 17.00 & $19.55^{b}$ & $11.28^{b}$ & $225.47^{a}$ & $129.25^{\mathrm{a}}$ & $29.11^{\mathrm{a}}$ & $7.07^{a b c}$ \\
\hline M1B1 & $39.13^{b}$ & 17.54 & $19.47^{b}$ & $11.46^{b}$ & $208.81^{a}$ & $128.48^{a}$ & $24.38^{\mathrm{abc}}$ & $7.99^{\mathrm{abc}}$ \\
\hline M1B2 & $41.24^{\mathrm{a}}$ & 16.39 & $19.55^{b}$ & $11.43^{b}$ & $208.81^{a}$ & $129.69^{a}$ & $24.55^{\mathrm{abc}}$ & $8.11^{\mathrm{abc}}$ \\
\hline M1B3 & $38.47^{\text {abc }}$ & 17.21 & $19.62^{b}$ & $11.36^{b}$ & $211.55^{\mathrm{a}}$ & $113.31^{\mathrm{ab}}$ & $30.91^{\mathrm{a}}$ & $6.50^{\mathrm{abc}}$ \\
\hline M2B1 & $38.01^{\mathrm{abc}}$ & 16.74 & $20.43^{a b}$ & $11.32^{b}$ & $209.63^{\mathrm{a}}$ & $110.35^{a b}$ & $27.06^{\mathrm{ab}}$ & $8.14^{\mathrm{abc}}$ \\
\hline M2B2 & 38.37 & 16.11 & $20.39^{a b}$ & $11.48^{b}$ & $198.29^{a}$ & $122.35^{a}$ & $24.90^{a b c}$ & $7.80^{\mathrm{abc}}$ \\
\hline M2B3 & $38.98^{b}$ & 16.53 & $22.17^{\mathrm{a}}$ & $12.84^{a}$ & $223.73^{a}$ & $131.37^{\mathrm{a}}$ & $24.19^{a b c}$ & $8.85^{\mathrm{ab}}$ \\
\hline
\end{tabular}

*Means followed by the common letter are not significant at 5\% DMRT.

Leaf Weight at Harvest (g).Heaviest leaves were observed in M2B0, $144.46 \mathrm{~g}$, and lightest in M0B3, 62.63g. Leaf weight in other treatments varied from $131.37 \mathrm{~g}$ to $1110.35 \mathrm{~g}$ in M2B3, M1B2, M1B0, M1B1, M2B2, M1B3, andM2B. The variation in leaf weight among treatments is directly related to the size of the leaves (leaf length, width, area) produced by the plants. Based on the other growth parameters, it can be noted that the longest and widest leaves and biggest leaf area were produced by the plants treated with bio-organic pestilizer from animal wastes and plant extracts. This implied that health and vigor of the plants were dueto nutrient intake from the bio-organic materials supplied to them. Gross et al., 2008, mentioned that organic fertilizers have the property to enhance soil aggregation, soilaeration, and water holding capacity; factors which offer good environmental condition to broccoli plants.

Weight of Whole Plant at harvest. Weight of whole plant at harvest was heaviest in M2B1, 247.02 g and M2B0, $245.29 \mathrm{~g}$, respectively. This is followed by M2B3 (232.95), M1BO (231.59), M1B1 (219.40), M1B3 (218.83), M2B2 (218.04)and M1B2 (215.00). Treatments

(M0B3-131.74 grams; M0B2-127.46 g and M0B1- $123.48 \mathrm{~g}$ ), without bio-pestilizer generally have the lightest plants. Weight of whole plant comprises all plant parts including the roots. The results of the study relative to the weight of the whole plant almost follow similar pattern with the other growth parameters evaluated such as the vegetative parts (leaf length, width and leaf area) and underground parts (root-shoot-ratio) which pointed out that the application of bio- fertilizer from animal waste (carabao manure with manure tea) had the tremendous effect in the excessive of growth of vegetative plants parts which resulted to the production of healthy plants. These results are in agreement with the findings of Caser (2009) in cauliflower, Elkhatib, (2009) on common bean.

Shoot-Root Ratio. Shoot-rootratio was highest in plants treated with DCM-1.5, $9.90 \mathrm{~g}$ followed by plants treated with DCM-1.5 with $8.85 \mathrm{~g}$ per plant. Other data showed insignificant difference in shoot-root ratioamong treatments. M0B1 has a shoot- root ratio of $5.29 \mathrm{~g}$. On the contrary, shoot- root ratio was lowest in treatment with carabao manure (with manure tea) and foliar bio-fertilizer and pesticide $(\mathrm{MOBO})$ at 4.66. Root development is strongly influenced by the growing conditions like available nutrients and environment stresses such that healthy roots generally produces healthy plants. The higher shoot-root ratio among treatment treated with bio- organic fertilizer is indicative that the plants were receiving sufficient nutrients to support a large vegetative (shoot) growth. Wright et al. (1995), observed that maximum root growth and rooting depth of barley crop were higher in treatments, which received animal manures relative to where manure was not applied. The results therefore suggest that the observed response was largely due to increased availability of $\mathrm{N}$ and $\mathrm{P}$ in Carabao manure and manure tea and consequently enhanced root growth.

\section{Yield Parameters}

Yield parameters as influenced by the application of bio-organic pestilizer are presented in Table 2.

Number of Days from Transplanting to $\mathbf{5 0 \%}$ Flowering.Days from transplanting to $50 \%$ flower or curd formation showed significant differences among the treatments. The number of days it took from transplanting to $50 \%$ flower/curd formation in plants applied with bio-organic pestilizer (M2B3, M2B1, and M2B2) was between 42.00 - 42.33 days, which is statistically at par with the rest of the treatments. Maximum number of days it took from transplanting to 50\% flowering/curd formation ranged from 47.33 to 52.00 days, were exhibited in treatments not applied with bio-pestilizer (M0B3 and M0B2). Notably, the cauliflower variety (Farmers' Extra Early) used in this study was an early maturing variety, produces curds which can be harvested within 40 days from transplanting. Based on the results, generally, plants which were organically fertilized flowered earlier compared to those whichwere not fertilized; possibly dueto better nourishment. The lack of nutrients for immediate utilization in control plants may have contributed to the delay in flower/curd formation. 
Vol. 4, No. 03; 2019

ISSN: $2456-8643$

Table 2. Yield Characters of Cauliflower as influenced by the Application of Bio-pestilizer from Animal Wastes and Plant Extracts

\begin{tabular}{|c|c|c|c|c|c|}
\hline \multirow[t]{2}{*}{ Treatments } & \multicolumn{5}{|c|}{ Mean* } \\
\hline & $\begin{array}{l}\text { Numberof Days } \\
\text { to } 50 \% \text { Flowering }\end{array}$ & $\begin{array}{l}\text { Curd diameter } \\
\text { harvest }(\mathrm{cm})\end{array}$ & at & $\begin{array}{l}\text { Weight ofmarketable } \\
\text { curd at harvest }(\mathrm{g})\end{array}$ & $\begin{array}{l}\text { Yield of marketable } \\
\text { curd(t/ha) }\end{array}$ \\
\hline M0B0 & $46.50^{\text {cd }}$ & $6.90^{\mathrm{e}}$ & & $78.78^{\mathrm{b}}$ & $0.43^{\mathrm{fg}}$ \\
\hline M0B1 & $46.67^{\mathrm{bcd}}$ & $8.49^{\text {cde }}$ & & $78.90^{\mathrm{b}}$ & $1.90^{\operatorname{defg}}$ \\
\hline M0B2 & $52.00^{\mathrm{a}}$ & $7.16^{\mathrm{e}}$ & & $67.11^{\mathrm{b}}$ & $4.39^{\mathrm{abcd}}$ \\
\hline M0B3 & $49.00^{\mathrm{ab}}$ & $8.02^{\mathrm{e}}$ & & $73.47^{\mathrm{b}}$ & $5.49^{\mathrm{ab}}$ \\
\hline M1B0 & $44.00^{\mathrm{cd}}$ & $10.14^{\mathrm{abc}}$ & & $196.25^{\mathrm{a}}$ & $0.54^{\mathrm{fg}}$ \\
\hline M1B1 & $47.33^{b c}$ & $9.34^{\mathrm{bcd}}$ & & $176.65^{\mathrm{a}}$ & $0.91^{\mathrm{efg}}$ \\
\hline M1B2 & $45.67^{\mathrm{bcd}}$ & $10.28^{\mathrm{abc}}$ & & $184.88^{\mathrm{a}}$ & $2.85^{\text {cdef }}$ \\
\hline M1B3 & $44.00^{\mathrm{cd}}$ & $10.47^{\mathrm{ab}}$ & & $179.26^{\mathrm{a}}$ & $5.46^{\mathrm{ab}}$ \\
\hline M2B0 & $42.50^{\mathrm{cd}}$ & $11.65^{\mathrm{a}}$ & & $204.69^{\mathrm{a}}$ & $0.14^{g}$ \\
\hline M2B1 & $42.33^{\mathrm{d}}$ & $11.94^{\mathrm{a}}$ & & $223.67^{\mathrm{a}}$ & $3.11^{\text {bcde }}$ \\
\hline M2B2 & $42.33^{\mathrm{d}}$ & $11.07^{\mathrm{ab}}$ & & $202.37^{\mathrm{a}}$ & $6.06^{\mathrm{a}}$ \\
\hline M2B3 & $42.00^{\mathrm{d}}$ & $12.08^{\mathrm{a}}$ & & $202.42^{\mathrm{a}}$ & $5.04^{\mathrm{abc}}$ \\
\hline
\end{tabular}

*Means followed by the common letter are not significant at 5\% DMRT.

The extended vegetative phase which caused the delayed flowering in untreated plants, aside from nutrient intake insufficiency, may be associated to environmental stress brought about by abnormal weather conditions.

Curd Diameter (cm) at Harvest. Curd diameter considerably differed among the treatments evaluated. Comparably, treatments (M0B3, M0B2, M0B1, and M0B0) with plants untreated with bio-organic pestilizer yield inferior curds. Statistically, the same curd sizes were observed in treatments $\mathrm{M} 2 \mathrm{~B} 3$, M2B1, and $\mathrm{M} 2 \mathrm{~B} 0$, varying from $12.08 \mathrm{~cm}$ to $11.65 \mathrm{~cm}$; significantly followed by those in treatments M2B2, $11.07 \mathrm{~cm}$, and M1B3, $10.47 \mathrm{~cm}$. M0B1 and M0B3 yielded smaller curds while smallest curds were prominent in M0B2 and M0B0.

Based from the results of the study, curd sized produced in plants receiving carabao manure as bio-organic fertilizer complemented with manure tea and foliar bio-spray were comparatively bigger than the unfertilized plants which can be attributed to early release of available nutrient 
specially phosphorus and nitrogen as a results of manure tea complementation which lead to better curd development.

Curd Weight at harvest. Of the twelve treatments evaluated in this study, heavier curds were significantly manifested in eight treatments (M1B0, M1B1, M1B2, M1B3, M2B0, M2B1, $\mathrm{M} 2 \mathrm{~B} 2$, and M2B3) applied with bio-organic pestilizer. Lightest curds were significantly evident in treatments (M0B1, M0B0, M0B3 and M0B), with unfertilized plants. In harmony with other growth and yield parameters evaluated in this study, treatments administered with bio-pestilizer also registered heavier curds. Better growth and yield performance are manifestations of nutrient sufficiency provided to the plants by the bio organic resources.

Average Yield of Marketable Curd Yield (t/ha). Marketable curd yield was highest in treatment with bio-organic pestilizer (M2B2) at $6.06 \mathrm{t} / \mathrm{ha}$. Lowest yield were taken from T9 at $0.14 \mathrm{t} / \mathrm{ha}$. High yield is the concrete manifestation of the overall plant performance given favourable environment (physically conducive and nutritionally sufficient).Expectedly, plants reared in such condition will produce big and heavy curds. Based on the production indices evaluated in this study, the application of bio-organic pestilizer (carabao manure, manure tea and foliar bio-spray) almost resulted to sizable vegetable growth.

\section{CONCLUSION AND RECOMMENDATIONS}

The application of bio-organic pestilizers from animal wastes and plant extracts was found to have highly influenced the growth and yield of cauliflowers, evident on the different growth and yield parameters evaluated, such as plant height, length and width of leaves, leaf area and weight at harvest, weight of whole plant, root-shoot-ratio, number of days to $50 \%$ flowering, weight and diameter of curd and yield of marketable curds. Higher rates of bio-organic pestilizer resulted to bigger and heavier plants and eventually higher yield of marketable cauliflowers. Bio- organic fertilizer from animal wastes (carabao manure with manure tea) was found to effective in influencing growth and yield of cauliflower while the efficacy and effectiveness of bio-organic fertilizer from plant extracts might have been affected by factors like dose, timing of and frequency of application, and stress factors brought about by abnornal environmental conditions during the conduct of the study.

The use of bio-organic fertilizer from animal wastes and plant extracts for sustainable organic cauliflower production given a favorable weather condtions would be economically viable and feasible under Samar conditions. Further verification is necessary to determine the performance of cauliflower using bio-organic pestilizer under farmers' field conditions in Samar, Philippines.

\section{Acknowledgement}

The researcher wish to express her profound thanks to the University of Eastern Philippines (UEP) administration for the material and financial support that leads in the realization of this experiment. To the University Research and Development Services staff, and field workers who assisted the researchers throughout the duration of the experimentation.

The Researcher 
Vol. 4, No. 03; 2019

ISSN: $2456-8643$

\section{REFERENCES}

Abou El- Magd, M.M., A.M, El-Bassiony and Z.F. Fawzy. 2016. Effectof Organic Manure with or Without Chemical Fertilizerson Growth, Yield and Quality of Some Varieties of Broccoli Plants

Alo,L.D. and Tuan, P.P. 2014. Growth and Yield of Cauliflower(Brassica oleracea) Applied with Chicken Dung-based Organic Fertilizer under Polyethylene Pot Culture. UEPGS MS Thesis.

Caser G. Abdel.2009. Improving the Production of Well Irrigated Cauliflower (Brassica oleraceavar.Botrytis,Cv. Snowball Y. Imp) by Foliar Spraying of some Growth Regulators. Journal of ZankoySulaimani12(1), 29-49.

DOST. (1998): Madre de cacao. Department of Science and Trade. Manila, Philippines.Stoll, G. (2000): Natural protection in the tropics. MargrafVer Weikersheim.www.bar.gov.ph

El-Dissoky, R. A. 2008. Studies on the use efficiency of potassium and organic fertilizers on potatoes and its role in improving soil properties. PhD Thesis.Faculty of Agriculture, Mansoura, University, Egypt.

Elkhatib HA. 2009. Growth and yield of common bean (Phaseolus vulgarisL.) in response to Rhizobium Inoculation, nitrogen and molybdenium fertilization. Alex. Sci.ExchangeJournal 30, 319- 332 .

El-Sawy, B. I., Radawan, E. A. and Hassan, N. A. 2000. Growth and yield of potato as affected by soil and foliar potassium application. Journal of Agriculture Science, 25(9):5843-5850.

El-Tantawy, I. M., El-Ghamry, A. M. and Habib, A. H. 2009.Impact of farmyard manure and compost tea on potato yield and soil fertility. Journal of Agriculture Science, 34(1): $669-678$.

Fayed, T. A. 2010. Optimizing yield, fruit quality and nutrient status of Roghiani olive grown in Libya using some organic extracts. Journal of Horticulture Science and Ornamental Plants, 2(2): 63-78.

Gross, A., Arusi, R. and Nejidat, A. 2007. Assessment of extraction methods with fowl manure for the production of liquid organic fertilizers. Bio-resource Technology, 99: 327-334.

Jigme1, Nipon Jayamangkala1, PathipanSutigoolabud, JiraponInthasan and Siriwat Sakhonwasee1.2015. The effect of Organic fertilizers on growth and yield of broccoli(Brassica oleraceaL. var. italicaPlenck cv. Top Green) Journal of Organic Systems, 10(1),

Rodriguez AA. January 2012. "Sariaya, Quezon Organic Farmer Succeeds with Cauliflower". Agriculture Monthly. Volume 16, Issue 01. p. 44.

Samonte P. August 2012 . "Bataan Farmer earns Millions from Calamansi and Vegetables". Agriculture Monthly. Volume 16, Issue 8. pp.20-21 
Samonte P. March 2013. "Organic Farming Develops Roots In Pampanga". Agriculture Monthly. Vol 17, Issue No. 3 pp 52-53.

PCARRD. 1999. Broccoli and Cauliflower Production Guide. Information Bulletin No.

148. Los Banos 4030 Laguna.

Rosco E.T., 2014. Executive Director, PhilRice Research Institute. Personal CommunicationTuan, P.P. 2002. Project Leader, UEP PATSARRD Project

Wright R. J., Hern J.L., Balingar V.C. and Bennet O.L.1995. The effects of surface applied soil amendments on barley root growth in an acid sub soil.

Communications in Soil Science and Plant Analysis. 16: 179-192.*Means followed by the common letter are not significant at 5\% DMRT. 